quoted nor referred to without permission of the author(s).

To be submitted to Journal of Applied Physics.

\title{
Effects of Hydrogen in the Annealing Environment On Photoluminescence from $\mathrm{Si}$ Nanoparticles in $\mathrm{SiO}_{2}$
}

\author{
S. P. Withrow, C. W. White, A. Meldrum, and J. D. Budai \\ Oak Ridge National Laboratory \\ Oak Ridge, Tennessee \\ D. M. Hembree, Jr. \\ Oak Ridge Y-12 Plant \\ Oak Ridge, Tennessee \\ and \\ J. C. Barbour \\ Sandia National Laboratories \\ Albuquerque, New Mexico
}

\begin{abstract}
"The submitted manuscript has been auhored by a contractor of the lis. Governucint under contract No. DEA(05.960) 22464 . Accordingly, the (S. Government retains a nonexclusive. royalty-free license to publish or reproduce the published form of this contribution, or allow others to do so. for I.S. Government purposes."
\end{abstract}

\footnotetext{
Prepared by the

Oak Ridge National Laboratory

Oak Ridge, Tennessee 37831

managed by

LOCKHEED MARTIN ENERGY SYSTEMS. INC.

for the

U.S. DEPARTMENT OF ENERGY

under contract DE-ACO5-96OR22460
}

February 1999

Sandia is a multiprogram laboratory operated by Sandia Corporation, $a$ Lockheed Martin Company, for the United States Department of Energy under contract DE-AC04-94AL85000. 


\section{DISCLAIMER}

This report was prepared as an account of work sponsored by an agency of the United States Government. Neither the United States Government nor any agency thereof, nor any of their employees, make any warranty, express or implied, or assumes any legal liability or responsibility for the accuracy, completeness, or usefulness of any information, apparatus, product, or process disclosed, or represents that its use would not infringe privately owned rights. Reference herein to any specific commercial product, process, or service by trade name, trademark, manufacturer, or otherwise does not necessarily constitute or imply its endorsement, recommendation, or favoring by the United States Government or any agency thereof. The views and opinions of authors expressed herein do not necessarily state or reflect those of the United States Government or any agency thereof. 


\section{DISCLAIMER}

Portions of this document may be illegible in electronic image products. Images are produced from the best available original document. 


\title{
Effects of Hydrogen in the Annealing Environment on Photoluminescence from Si
} Nanoparticles in $\mathrm{SiO}_{2}$

\author{
S. P. Withrow, C. W. White, A. Meldrum, and J. D. Budai \\ Oak Ridge National Laboratory, Oak Ridge, TN 37831 \\ D. M. Hembree, Jr. \\ Oak Ridge Y-12 Plant, Oak Ridge, TN 3783.1 \\ and \\ J. C. Barbour \\ Sandia National Laboratories, Albuquerque, NM
}

\section{$\underline{\text { Abstract }}$}

The role of hydrogen in enhancing the photoluminescence (PL) yield observed from Si nanocrystals embedded in $\mathrm{SiO}_{2}$ has been studied. $\mathrm{SiO}_{2}$ thermal oxides and bulk fused silica samples have been implanted with $\mathrm{Si}$ and subsequently annealed in various ambients including hydrogen or deuterium forming gases $\left(\mathrm{Ar}+4 \% \mathrm{H}_{2}\right.$ or $\left.\mathrm{Ar}+4 \% \mathrm{D}_{2}\right)$ or pure Ar. Results are presented for annealing at temperatures between $200^{\circ}$ and $1100^{\circ} \mathrm{C}$. Depth and concentration profiles of $\mathrm{H}$ and $\mathrm{D}$ at various stages of processing have been measured using elastic recoil detection. Hydrogen or deuterium is observed in the bulk after annealing in forming gas but not after high temperature $\left(1100^{\circ} \mathrm{C}\right)$ anneals in Ar. The presence of hydrogen dramatically increases the broad PL band centered in the near-infrared after annealing at $1100^{\circ} \mathrm{C}$ but has almost no effect on the PL spectral distribution. Hydrogen is found to selectively trap in the region where $\mathrm{Si}$ nanocrystals are formed, consistent with a model of $\mathrm{H}$ passivating surface states at the $\mathrm{Si} / \mathrm{SiO}_{2}$ interface that leads to enhanced PL. The thermal stability of the trapped $\mathrm{H}$ and the PL yield observed after a high temperature anneal have been studied. The hydrogen concentration and PL yield are unchanged for subsequent anneals up to $400^{\circ} \mathrm{C}$. However, above $400^{\circ} \mathrm{C}$ the PL decreases and a more complicated $\mathrm{H}$ chemistry is evident. Similar concentrations of $\mathrm{H}$ or $\mathrm{D}$ are trapped after annealing in $\mathrm{H}_{2}$ or $\mathrm{D}_{2}$ forming gas; however, no differences in the PL yield or spectral distribution are observed, indicating that the electronic transitions resulting in luminescence are not dependent on the mass of the hydrogen species. 


\section{Introduction}

Significant effort has been focused in recent years on the formation and characterization of $\mathrm{Si}$ nanocrystals. This interest originated with the observation of room temperature photoluminescence (PL) from porous silicon ${ }^{1}$ and the interpretation of the light emission in terms of quantum confinement of carriers in nanocrystalline-sized Si structures. In subsequent studies PL has been observed from nanometer-sized crystalline Si particles fabricated using a variety of techniques, including deposition onto substrates by gas phase synthesis or decomposition of silane by plasmas or lasers. Another process that has been widely used for Si nanocrystal formation involves ion implantation of Si into $\mathrm{SiO}_{2}$ followed by thermal annealing. ${ }^{2-12}$ At sufficiently high temperatures the implanted excess $\mathrm{Si}$ precipitates out from the $\mathrm{SiO}_{2}$ resulting in embedded $\mathrm{Si}$ particles. This approach to synthesis appears well-suited for optoelectronic device applications since the particles formed are in a mechanically robust and chemically stable matrix, the technique allows for some control over nanocrystal size and distribution via processing conditions, and the procedure could be integrated into standard device technologies. Light emitting devices based on nanocrystalline Si would have potential applications in adranced microelectronics. Other applications, including memory structures utilizing charged $\mathrm{Si}$ nanocrystals, ${ }^{13}$ have also been proposed.

While photoluminescence has been observed from samples utilizing ion implantation of $\mathrm{Si}$ into $\mathrm{SiO}_{2}$ to form nanocrystals, the origin of the light emission is still being debated. The phenomenon has been attributed to quantum confinement effects by some authors, but it is difficult to reconcile all the dala to this model. ${ }^{1+}$ Other mechanisms, including states at the nanocrystal-Si/SiO 2 interface and/or processing-induced defects. may also play a significant role in the emission. One of the parameters that affects the photoluminescence is the presence of hydrogen. A number of authors have studied the effects hydrogen has on the PL observed from Si nanocrystals in $\mathrm{SiO}_{2}$. Min et al. ${ }^{4}$ reported that implanting deuterium following ion beam synthesis of $\mathrm{Si}$ nanocrystals in $\mathrm{SiO}_{2}$ quenches luminescence related to defects in the matrix. Subsequent annealing at $500^{\circ} \mathrm{C}$ in vacuum resulted in a large increase (up to 10-fold) in PL related to the nanocrystals which they attributed to mobility of $D$ in the substrate 
and trapping at dangling bonds at the $\mathrm{SiO}_{2} / \mathrm{Si}$ interface. Neufeld et al. ${ }^{3}$ observed that annealing Siimplanted $\mathrm{SiO}_{2}$ in a rapid thermal annealing furnace in a $\mathrm{H}_{2} / \mathrm{N}_{2}$ ambient increased the PL by a factor of 3 over a vacuum anneal and attributed this reversible change to the passivation of non-radiative defects by hydrogen. To date, however, no direct measurement of the hydrogen concentration in luminescent samples has been reported.

In the present work, a systematic study of the effects of hydrogen on the PL from Si nanocrystals in $\mathrm{SiO}_{2}$ is presented. Hydrogen concentrations and depth profiles have been measured in $\mathrm{SiO}_{2}$ containing Si nanocrystals and correlated with photoluminescence spectra. While luminescence is seen in samples where no $\mathrm{H}$ is measured, the presence of $\mathrm{H}$ dramatically increases the PL yield but has almost no effect on the PL spectral distribution. In addition, the $\mathrm{H}$ selectively traps in the region of the Si nanocrystals at a concentration that is consistent with interface passivation. No hydrogen isotope effects are seen.

\section{Experiment}

Si ions were implanted at room temperature into thermal oxide films grown on $\mathrm{Si}(100)$ wafers or into bulk fused silical (Corning 7940 glass) substrates. Ion energies between 100 and $400 \mathrm{keV}$ and doses from $1-6 \times 10^{17} / \mathrm{cm}^{2}$ were utilized to produce peak excess $\mathrm{Si}$ concentrations of 0.5 $2 \times 10^{12} / \mathrm{cm}^{3}$. Uniform excess Si concentrations of up to $2 \times 10^{22} / \mathrm{cm}^{3}$ were produced in several samples by multiple energy implantations. The implanted samples were subsequently furnace annealed at $1100^{\circ} \mathrm{C}$ for 1 hour to precipitate $\mathrm{Si}$ into nanoparticles. Annealing was carried out in several different atmospheres, including flowing $\mathrm{Ar}+4 \% \mathrm{H}_{2}$ forming gas, $\mathrm{Ar}+4 \% \mathrm{D}_{2}$ forming gas, or an Ar-only ambient. Samples were removed from the furnace but remained in the ambient to cool radiatively (to $<700^{\circ} \mathrm{C}$ in $\sim 20 \mathrm{~s}$ ). Alternately, a few samples were held in the furnace and cooled slowly to room temperature over several hours. Selected samples were annealed a second time at various temperatures up to $1100^{\circ} \mathrm{C}$. 
The presence of Si nanocrystals was directly observed using transmission electron microscopy and $\mathrm{x}$-ray diffraction. Photoluminescence spectra were obtained at room temperature with a double pass spectrometer using the 514-nm line from an Ar ion laser for excitation and a photomultiplier for detection. Concentration profiles of $\mathrm{H}$ in the oxides were measured using elastic recoil detection (ERD) of a $24 \mathrm{MeV} \mathrm{Si}^{+5}$ ion beam incident at 75 degrees from the surface normal. Recoiled $\mathrm{H}$ was detected at a forward scattering angle of 30 degrees in a surface barrier detector behind a 12-micron mylar foil. The experimental geometry was calibrated, just before data collection from the $\mathrm{SiO}_{2}$ samples, using a $300 \mathrm{~nm}$ thick $\mathrm{Si}_{3} \mathrm{~N}_{4}$ standard sample with a uniform concentration depth profile of 6 at. $\% \mathrm{H}$. Depths down to $800 \mathrm{~nm}$ in the $\mathrm{SiO}_{2}$ could be probed using the ERD technique with a depth resolution of $30-50 \mathrm{~nm}$. D was depth profiled in selected samples using the same technique.

\section{$\underline{\text { Results }}$}

If $\mathrm{Si}$-implanted $\mathrm{SiO}_{2}$ is annealed at $1100{ }^{\circ} \mathrm{C}$, then precipitation of the excess $\mathrm{Si}$ occurs. The transmission electron microscopy (TEM) images shown in Figure 1 confirm the formation of nanocrystals in the Si-implanted $\mathrm{SiO}_{2}$ wafers. For a uniform excess $\mathrm{Si}$ concentration of $5 \times 10^{21}$ ions $/ \mathrm{cm}^{3}$ achieved by multiple energy implants, separate and well-defined regions of dark contrast having an average diameter of approximately $3 \mathrm{~nm}$ are readily visible using slightly defocused imaging conditions (Fig. 1a). Continuous lattice fringes were not observed: however, these regions of dark contrast did not occur in the unimplanted portion of the specimen. The dark contrast areas are. therefore. tentatively identified as silicon-rich clusters. In a sample with a uniform excess Si concentration of $2 \times 10^{22}$ ions $/ \mathrm{cm}^{3}$, relatively large $(>5 \mathrm{~nm})$, well-defined nanocrystals were observed (Fig. 1b). The distribution of nanocrystal sizes is relatively broad in this sample. An additional specimen implanted with a single ion energy $\left(400 \mathrm{keV}, 1.5 \times 10^{17}\right.$ ions $\left./ \mathrm{cm}^{2}\right)$ also showed a broad distribution of nanocrystal sizes after annealing at $1100^{\circ} \mathrm{C}$. The largest particles were located at a region corresponding the peak concentration of implanted Si, and the smaller particles were located at the tails 
of the implant distribution. The average size of the Si precipitates is, therefore, largely dependent on the concentration of implanted silicon.

Figure 2 shows PL spectra obtained from fused silica implanted with $400 \mathrm{keV} \mathrm{Si}$ to a dose of $1.5 \times 10^{17} \mathrm{Si} / \mathrm{cm}^{2}$. The PL from the as-implanted sample peaks at $650 \mathrm{~nm}$ and arises from defects introduced into the matrix during implantation. ${ }^{7}$ Annealing at $950^{\circ} \mathrm{C}$ greatly reduces this defect luminescence and may induce formation of small nanoparticles. After annealing at $1100^{\circ} \mathrm{C}, \mathrm{Si}$ nanoparticles are visible in TEM and an intense PL band peaked at $\sim 750 \mathrm{~nm}$ is observed.

Figure 3 shows PL spectra from fused silica implanted with Si $\left(200 \mathrm{keV}, 1.0 \times 10^{17} / \mathrm{cm}^{2}, \mathrm{RT}\right)$ and then annealed for $1 \mathrm{~h}$ at $1100^{\circ} \mathrm{C}$ in three different environments. A broad peak centered at just less than $750 \mathrm{~nm}$ is observed when the ambient is flowing $\mathrm{Ar}+4 \% \mathrm{H}_{2}$. A spectrum with the same intensity and spectral distribution is obtained when the $4 \%$ hydrogen is replaced with $4 \%$ deuterium (dashed curve). A sample annealed in an Ar ambient at the same temperature and for the same length of time has a PL yield lower by a factor of approximately four. Hence the intensity of the PL is strongly dependent on the presence of hydrogen in the annealing environment. However, the spectral distribution is the same as annealing in $\mathrm{Ar}+4 \% \mathrm{H}_{2}$.

Results similar to those in Fig. 3 are observed for Si nanocrystals formed in a thermal oxide on Si. For the latter substrates, however, PL yields are typically higher by 30 to $50 \%$. The source of this increased PL may be related to partial reflection of the incident laser light from the $\mathrm{SiO}_{2} / \mathrm{Si}$ interface, resulting in increased excitation. Interference effects in the PL spectrum due to reflection of the excitation light at an interface was previously observed to cause resonant PL results seen for Ge nanoparticles in thermal $\mathrm{SiO}_{2}$ layers. ${ }^{15}$

For the sample in Fig. 3 that was annealed in $\mathrm{Ar}$, a subsequent $1100^{\circ} \mathrm{C}$ anneal in $\mathrm{Ar}+4 \% \mathrm{H}_{2}$ results in an increase in $\mathrm{PL}$ to nearly the same vield obtained for the $\mathrm{Ar}+4 \% \mathrm{H}_{2}$ anneal. By alternating between 
Ar and forming gas anneals the PL can be cycled between higher and lower yields, indicating that the hydrogen effect is reversible. It should be noted, however, that is not possible to reproduce the same yields indefinitely by cycling since the PL yield is also a function of annealing time. For a uniform implantation of $5 \times 10^{21} / \mathrm{cm}^{3}$ the PL reaches a maximum after annealing for $1 \mathrm{~h} \mathrm{at} 1100^{\circ} \mathrm{C}$ in hydrogen forming gas. Annealing this sample for $24 \mathrm{~h}$ at $1100^{\circ} \mathrm{C}$ results in a reduction in PL yield of more than $80 \%$. This decrease is believed due to Ostwald ripening of the nanoparticles coupled with an inverse size-dependence for luminescence. A PL dependence on annealing time has previously been reported. ${ }^{7}$

The spectra presented in Fig. 3 show that the annealing ambient has a strong effect on the PL yield. In particular, the presence of $\mathrm{H}_{2}$ (or $\mathrm{D}_{2}$ ) in the ambient leads to an increased PL over that observed after annealing in only Ar. To understand these results, profiles of hydrogen in the surface layer of the oxide after different processing conditions have been obtained using elastic recoil detection. The hydrogen distribution in a thermal oxide implanted with $\mathrm{Si}\left(200 \mathrm{keV}, 1 \times 10^{17} / \mathrm{cm}^{2}\right.$, RT) is given by the dotted curve in Fig. 4. The large peak at the surface is attributed to adsorbed $\mathrm{H}$ or surface contamination such as water or hydrocarbons. This peak is commonly observed for unannealed $\mathrm{SiO}_{2}$ or $\mathrm{SiO}_{2} / \mathrm{Si}$ samples. The bulk $\mathrm{H}$ concentration in this as-implanted sample, $\sim 0.06$ at. $\%$, is uniform with depth down to $800 \mathrm{~nm}$, which is the depth that the ERD technique can probe in these samples without interference from an oxygen signal. The same level and distribution of $\mathrm{H}$ was measured in the unimplanted thermal oxide indicating implantation does not affect the $\mathrm{H}$ concentration. The noise levels in the spectra are \pm 0.02 at. \%. A similar uniform $\mathrm{H}$ profile, but at twice the $\mathrm{H}$ concentration, has been measured in an unimplanted fused silica sample, indicating that the amount of $\mathrm{H}$ incorporated into the oxide varies with the $\mathrm{SiO}_{2}$ preparation technique. Also shown in Fig. 4 for comparison are spectra obtained after annealing at $1100^{\circ} \mathrm{C}$ for $1 \mathrm{~h}$ either in $\mathrm{Ar}+4 \% \mathrm{H}_{2}$ (solid curve) or only $\mathrm{Ar}$ (dashed curve). Each of these spectra shows a decrease in the surface $H$ concentration by roughly a factor of four, consistent with the high temperature anneal driving off surface contaminants. For the Ar-only annealed sample no detectable bulk $\mathrm{H}$ remains, indicating the uniform $\mathrm{H}$ concentration observed in the 
sample before annealing has diffused out of the region probed as a result of the $1100^{\circ} \mathrm{C}$ anneal. In contrast, when a sample is heated to the same temperature, $1100^{\circ} \mathrm{C}$, and subsequently cooled with $\mathrm{H}_{2}$ in the ambient, then $\mathrm{H}$ is observed in the bulk. However, the $\mathrm{H}$ is no longer distributed throughout the sample, as was the case before annealing, but is now limited to a profile with a peak at a depth of $\sim 300$ $\mathrm{nm}$ with a distribution that can be reasonably fit with a Gaussian. No $\mathrm{H}$ is detectable deeper than roughly $700 \mathrm{~nm}$.

The PL yields and the retained hydrogen profiles given in Figs. 3 and 4 were all obtained following $1100^{\circ} \mathrm{C}$ anneals. Additional information about the effect of $\mathrm{H}$ on PL in these samples was obtained using subsequent lower temperature anneals. Thermal oxide samples were processed in hydrogen forming gas under conditions that produce the higher PL yield seen in Fig. $3\left(1 \mathrm{~h}\right.$ at $1100^{\circ} \mathrm{C}$ ) and then annealed a second time for $1 \mathrm{~h}$ in Ar-only at selected temperatures between 200 and $1100^{\circ} \mathrm{C}$. In Fig. 5 are plotted the maximum in the PL yield from these twice-annealed samples (open circles) and also the peak retained $\mathrm{H}$ (open squares) as a function of the temperature of the second anneal. Also shown for comparison are the peak yields from Fig. 3 for annealing once at $1100^{\circ} \mathrm{C}$ for $1 \mathrm{~h}$ in $\mathrm{Ar}+4 \% \mathrm{H}_{2}$ (solid circle) or Ar (triangle). As seen in Fig. 5, for second anneal temperatures up to $400^{\circ} \mathrm{C}$ there is no effect on the measured PL or retained $\mathrm{H}$ relative to one anneal in $\mathrm{Ar}+4 \% \mathrm{H}_{2}$. However, between 400 and $800^{\circ} \mathrm{C}$ the PL yield decreases with increasing temperature. A second anneal at $800^{\circ} \mathrm{C}$ results in the same PL measured from a sample annealed once for th in Ar-only. These PL changes above $400^{\circ} \mathrm{C}$ are accompanied by changes in the $\mathrm{H}$ concentration, first an increase between 400 and $600^{\circ} \mathrm{C}$ and then a decrease at higher temperatures. Both the increase and the decrease are associated with changes in the $\mathrm{H}$ chemistry, including detrapping and diffusion. These effects are discussed below. It should be noted that the PL decrease seen in Fig. 5 is not a result of the Ostwald ripening process mentioned above. The PL yield changes only about $10 \%$ for anneals between $\mathrm{I}$ and $2 \mathrm{~h}$ at $1100^{\circ} \mathrm{C}$ in $\mathrm{Ar}+4 \% \mathrm{H}_{2}$ and would be expected to change even less at lower temperatures. 
Elastic recoil detection has also been used to measure the deuterium retained in a thermal oxide following an $1100^{\circ} \mathrm{C}$ anneal in deuterium forming gas. The spectrum is given in Fig. 6. Except for the ambient gas, the substrate and processing were the same as used for the ERD results in Fig. 4. The deuterium profile is qualitatively the same as for annealing in a hydrogen forming gas, indicating that hydrogen and deuterium behave similarly. No D peak at the surface is seen, evidence that the hydrogen in the surface peak in Fig. 4 is not a result of the annealing. A hydrogen profile was also measured from the sample that underwent a deuterium forming gas anneal. The $\mathrm{H}$ in the bulk in the as-implanted sample has been essentially removed as a result of the anneal but a hydrogen peak is seen on the surface. No D is seen in samples annealed in hydrogen forming gas, as expected.

\section{Discussion}

Hydrogen is known to exist in silicon dioxide in several chemical states: as interstitial molecular hydrogen $\mathrm{H}_{2}$, bonded directly to $\mathrm{Si}$, and as the hydroxyl $\mathrm{OH}^{-}$with the $\mathrm{OH}$ radicals either interstitial or attuched to dangling $\mathrm{Si}$ bonds. The amount of hydrogen in the $\mathrm{SiO}_{2}$ and its chemistry are dependent on the oxide preparation and subsequent processing. The concentration of $\mathrm{H}$ observed in the unimplanted oxide samples used here, on the order of 0.1 atomic percent, is consistent with a large body of work reviewed by Revesz ${ }^{14}$ which reported the presence of $10^{19}-10^{20}$ hydrogen species per $\mathrm{cm}^{3}$ as $\mathrm{Si}-\mathrm{OH}$ and $\mathrm{Si}-\mathrm{H}$ groups in steam- and $\mathrm{O}_{2}$-grown thermal oxides, respectively. Fused silica is also known to contain similar $\mathrm{H}$ amounts. ${ }^{15}$ At room temperature hydrogen is stable in the oxide. Fink reported no change in the hydrogen distribution in silica over long times, indicating that detrapping and diffusion are not significant at $\mathrm{RT}^{16}$ In contrast, $\mathrm{H}$-containing species are mobile in the lattice at elevated temperatures. For example, $\mathrm{OH}$ radicals trapped in the bulk oxide can be released at annealing temperatures $\geq 600^{\circ} \mathrm{C}^{17}$ The large open structure of $\mathrm{SiO}_{2}$ facilitates interstitial diffusion, with the movement affected (hindered) by the equilibrium between the $\mathrm{H}_{z}$ and $\mathrm{OH}$ radical and by trapping and detrupping of the hydrogen species at dangling bond sites. Heating at temperatures sufficiently high that $\mathrm{H}$ detraps and/or diffuses leads to changes in the ERD spectra. Although the ERD results 
presented here do not distinguish the bonding of the hydrogen, by correlation to PL spectra some interesting conclusions can be drawn about the effects of hydrogen on the luminescence.

Implantation does not change the bulk hydrogen concentration or distribution. While the number of dangling Si bonds in the region of the implant would be expected to increase as a result of implantation damage, $\mathrm{H}$ does not diffuse to this region at $\mathrm{RT}$ either from the surface or from deeper in the bulk. On the other hand, significant changes in the $\mathrm{H}$ profile are induced by thermal processing. Following annealing at $1100^{\circ} \mathrm{C}$ hydrogen remains in the bulk, but only in the region of the Si implant. No hydrogen is observed in the bulk of an unimplanted sample after an $1100^{\circ} \mathrm{C}, 1 \mathrm{~h}$ anneal in hydrogen forming gas (although hydrogen associated with the surface is present for this case). Hence, the Si implant and/or subsequent formation of nanocrystals provides the trapping sites necessary to retain H. In Fig. 7 a TRIM ${ }^{18}$ calculation (solid line) of the implant profile for $200 \mathrm{keV} \mathrm{Si}$ into $\mathrm{SiO}_{2}$ is compared to the bulk $\mathrm{H}$ concentration (dotted line) from Fig. 4 for an anneal in forming gas. Surface hydrogen in the ERD spectrum has been fit with a Gaussian and subtracted off. The theoretical implant profile peaks at $320 \mathrm{~nm}$ which is nearly identical to the broad maximum in the $\mathrm{H}$ distribution. This agrcement indicates a correlation between the implant and the trapped $\mathrm{H}$. On the other hand, the distribution widths differ, with the TRIM calculation extending down to $\sim 500 \mathrm{~nm}$ while the $\mathrm{H}$ distribution is broader and measureable down to almost $800 \mathrm{~nm}$. Part of this difference can be attributed to the depth resolution of the ERD measurements, $\sim 50 \mathrm{~nm}$, as can be inferred from the width of the $\mathrm{H}$ peak at the surface in Fig. 4. The broader $\mathrm{H}$ profile indicates that the amount of $\mathrm{H}$ trapped is not proportional to the local excess implant $\mathrm{Si}$ concentration. It has been suggested that the $\mathrm{H}$ is retained at the $\mathrm{SiO}_{2} / \mathrm{Si}$ interface where it passivates dangling bonds. ${ }^{3.4}$ If the amount of $\mathrm{H}$ retained is proportional to the surface area of the nanocrystals, the net effect would be to broaden the $\mathrm{H}$ distribution relative to the implant concentration. This is because the size of the nanocrystals varies across the implant profile, with the average size related to the implanted concentration. Smaller nanocrystals have a larger surface-to-volume ratio and would trap relatively more $\mathrm{H}$. 
It is interesting to consider where the $\mathrm{H}$ is located. After annealing, $\mathrm{H}$ is selectively seen only in the layer containing Si nanocrystals. That observation, plus the enhancement effect it has on the PL yield, supports the conclusion that $\mathrm{H}$ is trapped at the $\mathrm{Si} / \mathrm{SiO}_{2}$ interface. Selective accumulation of $\mathrm{D}$ at a SiO2/Si interface for annealing at temperatures up to $230^{\circ} \mathrm{C}$ has been previously reported. ${ }^{20}$ While a direct verification of this hypothesis is not possible here, a comparison between the measured amount of $\mathrm{H}$ versus the number of available surface states does suggest it is quantitatively reasonable. The measured peak $\mathrm{H}$ concentration of 0.06 at.\% occurs at a depth where the excess $\mathrm{Si}$ implant concentration is $5 \times 10^{21} / \mathrm{cm}^{3} .{ }^{19}$ As seen in Fig. la, this excess $\mathrm{Si}$ and the annealing conditions used produce precipitates of $\sim 3 \mathrm{~nm}$. If it is assumed that all the implanted Si at the peak of the profile precipitates into $3 \mathrm{~nm}$ nanocrystals and that all the measured $\mathrm{H}$ is on the nanocrystal interface, the $\mathrm{H}$ density would be $2 \times 10^{13} \mathrm{H} / \mathrm{cm}^{2}$. This $\mathrm{H}$ density is somewhat higher than the total interface state density expected at the $\mathrm{SiO}_{2} / \mathrm{Si}$ interface..$^{20}$

Annealing in either hydrogen or deuterium forming gas enhances the PL. While it may not be surprising that both isotopes have a similar effect, it is significant that there is no isotopic effect observed in the PL. Hydrogen and deuterium have an equivalent effect on both the PL yield and spectral distribution. From this latter result it can be concluded that the mechanism responsible for the PL does not involve transition energy levels that are isotope dependent. This result is in contrast to a recent study on the hydrogen isotope effect on luminescence from porous Si. Porous silicon passivated with D has a PL yield significantly blue shifted in comparison to an identical sample passivated with $\mathrm{H}^{21}$ This shift has been explained in terms of energy level differences in isotopedependent vibrational surface states involved in the radiative transitions. Clearly these results differ markedly from what is found here and suggest that the mechanisms for the PL are different.

The temperature at which $\mathrm{H}$ becomes mobile in these samples, $>400^{\circ} \mathrm{C}$, can be inferred from Fig. 5. Annealing below this temperature causes no changes either in the measured $\mathrm{H}$ or in the PL yield. On the other hand. at higher temperatures changes are seen and the relation between the bulk $\mathrm{H}$ and PL 
becomes more complicated. The small increase in $\mathrm{H}$ seen following $\mathrm{Ar}$ anneals at 500 and $600^{\circ} \mathrm{C}$ indicates that hydrogen diffuses into the implanted region at these temperatures either from the surface or possibly from the interface between the oxide and the Si substrate (the only available sources of $\mathrm{H}$ ). However, the corresponding decrease in PL indicates that in addition to hydrogen diffusing in, the configuration of the bulk hydrogen that enhances PL also undergoes a change. Between 600 and $800^{\circ} \mathrm{C}$ there is a PL yield decrease as the amount of $\mathrm{H}$ trapped decreases. This correlation suggests that as the second anneal temperature is increased in the temperature range between 400 and $800^{\circ} \mathrm{C}$, the amount of hydrogen trapped at the interface which affects the PL yield decreases. Johnson et al. observed a release of $\mathrm{D}$ at the $\mathrm{SiO}_{2} / \mathrm{Si}$ interface for vacuum anneals above $500^{\circ} \mathrm{C}^{20}$ The $\mathrm{PL}$ yield is function of the amount of $\mathrm{H}$ trapped in a specific bonding configuration at the interface, whereas the $\mathrm{H}$ measurement can include other $\mathrm{H}$ in the bulk (or at the interface) that does not affect the PL. By $800^{\circ} \mathrm{C}$ the PL yield has fallen to a level which is observed for an Ar only anneal at $1100^{\circ} \mathrm{C}$ (for which no $\mathrm{H}$ remains as seen in Fig. 4). Hence the $\mathrm{H}$ remaining in the sample in Fig. 5 after a second $800^{\circ} \mathrm{C}$ anneal would appear to have no effect on the PL. It should be noted that the observation of a PL yield in the absence of measurable hydrogen, or when the $\mathrm{H}$ is configured such as not to effect the PL, indicates that $\mathrm{H}$ is not required to explain the mechanism of luminescence. Radiative recombination can occur without hydrogen passivation. It has been suggested that other species, such as oxygen bonded to the Si at the nanocrystal interface, also may offer some degree of passivation." It is important to note that the PL observed in the absence of measurable $\mathrm{H}$ has the same spectral distribution as with measureable H. Clearly the mechanism for the PL and the mechanism for $\mathrm{H}$ enhancing the PL are independent.

In conclusion, quantitative profiles of hydrogen have been measured in fused silica and thermal $\mathrm{SiO}_{2}$ layers that have been implanted and annealed to form $\mathrm{Si}$ nanocrystals. The hydrogen is selectively trapped in the region of the nanocrystals and enhances the PL yield significantly, supporting a model for PL involving increased radiative emission as a result of hydrogen passivation of defects at the nanocrystal/SiO interface. At annealing temperatures greater than $\sim 400^{\circ} \mathrm{C}$ the hydrogen is mobile. and at $600^{\circ} \mathrm{C}$ moves away from the region of the nanocrystals with an accompanying decrease in PL 
yield. This suggests a PL yield dependent on the amount of $\mathrm{H}$ trapped at the interface, although bulk hydrogen that does not appear to affect the PL yield complicates this observation. Information on the bonding configuration of the $\mathrm{H}$ is needed to get a better understanding the hydrogen role. Photoluminescence is observed from samples that have been processed such that no hydrogen is measured using the ERD technique, indicating radiative recombination occurs with no or low levels of hydrogen present. Finally, annealing in either a hydrogen or deuterium forming gas ambient results in equivalent PL yields and spectral distributions which means that the hydrogen species, while enhancing the PL yield, it is not involved directly in the radiative emission mechanism.

\section{Acknowledgements}

Oak Ridge National Laboratory is managed by Lockheed Martin Energy Research Corp. for the U.S. Deparment of Energy under contract number DE-AC05-96OR22464. Sandia is a multiprogram laboratory operated by Sandia Corporation, a Lockheed Martin Company. The work at Sandia was supported by the U.S. DOE Office of Basic Energy Sciences (Division of Materials Sciences/Mctals and Ceramics) under contract DE-AC04-94AL85000. 


\section{$\underline{\text { References }}$}

1. L. T. Canham, Appl. Phys. Lett. 57, 1046 (1990).

2. C. W. White, J. D. Budai, S. P. Withrow, J. G. Zhu, E. Sonder. R. A. Zuhr, A. Meldrum, D. M. Hembree, Jr., D. O. Henderson, and S. Prawer, Nucl. Instrum. Methods in Phys. Res. B 141, 228 (1998); C. W. White, S. P. Withrow, A. Meldrum, J. D. Budai, D. M. Hembree, J. G. Zhu, D. O. Henderson, and S. Prawer, Mat. Res. Soc. Proc., vol. 507, (1998).

3. E. Neufeld, S. Wang, R. Apetz, Ch. Buchal, R. Carius, C. W. White, and D. K. Thomas, Thin Solid Films 294, 238 (1997).

4. K. S. Min, K. V. Shcheglov, C. M. Yang, Harry A. Atwater, M. L. Brongersma, and A. Polman, Appl. Phys. Lett. 69, 2033 (1996).

5. H. A. Atwater, K. V. Shcheglov, S. S. Wong, K. J. Vahala, R. C. Flagan, M. L. Brongersma, and A. Pohlman, Mat. Res. Soc. Symp. Proc. 316, 409 (1994); M. L. Brongersma, A. Polman. K. S. Min, and H. A. Atwater, J. Appl. Phys., submitted

6. T. Shimizu-Iwayama, S. Nakao. K. Saitoh, and N. Itoh, J. Phys.: Condensed Matter 6, L601 (1994); T. Shimizu-Iwayama, Norihiro Kurumado, David E. Hole, and Peter D. Townsend, J. Appl. Phys 83, 6018 (1998).

7. T. Shimizu-Iwayama, K. Fujita. S. Nakao, K. Saitoh, T. Fujita, and N. Itoh, J. Appl. Phys. 75 , 7779 (1994).

8. P. Mutti. G. Ghislotti, S. Bertoni, L. Bonoldi, G. F. Cerofolini, L. Meda, E. Grilli, and M. Guzzi. Appl. Phys. Lett. 66. 851 (1995).

9. T. Komoda. J. P. Kelly, A. Nejim. K. P. Homewood, P. L. F. Hemment, and B. J. Sealy, Mat. Res. Soc.Symp. Proc. 358, 163 (1995).

10. T. Fischer. V. Petrova-Koch. K. Shcheglov, M. S. Brandt, and F. Koch, EMRS Spring Meeting. 1995. 
11.L.-S. Liao, X.-M. Bao, X.-Q. Zheng, N.-S. Li, and N.-B. Min, Appl. Phys. Lett. 68, 850 (1996).

12. G. A. Kachurin, K. S. Zhuravlev, N. A. Pazdnikov, A. F. Leier, I. E. Tyschenko, V. A. Volodin, W. Skorupa, and R. A. Yankov, Nucl. Instrum. Methods in Phys Res. B 127/128, 583 (1997).

13. Sandip Tiwari, Farhan Rana, Hussein Hanafi, Allan Hartstein, Emmanuel F. Crabbé, and Kevin Chan, Appl. Phys. Lett. 68, 1377 (1996).

14. G. Revesz, J. Electrochemical Soc. 126, 122 (1979).

15. David L. Griscom, J. Appl. Phys. 58, 2524 (1985).

16. D. Fink, J. Krauser, D. Nagengast, T. Almeida Murphy, J. Erxmeier, L. Palmetshofer, D. Briunig, and A. Weidinger, Appl. Phys. A 61, 381 (1995).

17. R. A. B. Devine, J. Appl. Phys. 56, 563 (1984).

18. J. F. Ziegler, "Transport of Ions in Matter" (TRIM 98), IBM Corp. Software, (1998); J. F. Ziegler. J. P. Biersack, and U. Littmark, The Stopping and Range of Ions in Solids, ed. by J. F. Ziegler (Pergamon Press. New York, 1985) vol. 1.

19. TRIM calculation of the peak concentration corresponding to $200 \mathrm{keV}, 1 \times 1017 \mathrm{Si} / \mathrm{cm} 2$.

20. N. M. Johnson, D. K. Biegelsen, and M. D. Moyer, J. Vac. Sci. Technol. 19, 390 (1981).

21. Takahiro Matsumoto. Yasuaki Masumoto, Shinichi Nakashima, and Nobuyoshi Koshida. Thin Solid Films 297, 31 (1997).

22. L. N. Dinh. L. L. Chase, M. Balooch. W. J. Siekhaus, and F. Wooten, Phys. Rev. B5t, 5029 (1996). 


\section{Figure Captions}

1. Cross-section micrographs showing $\mathrm{Si}$ nanocrystals formed in $\mathrm{SiO} 2$ following annealing of uniform excess Si implantation of (a) $5 \times 10^{21} / \mathrm{cm}^{3}$ and (b) $2 \times 10^{22} / \mathrm{cm}^{3}$ at $1100^{\circ} \mathrm{C}$ for $1 \mathrm{~h}$ in flowing $\mathrm{Ar}+4 \% \mathrm{H}_{2}$.

2. PL spectra from $\mathrm{Si}\left(400 \mathrm{keV}, 1.5 \times 10^{17} / \mathrm{cm}^{2}\right.$, RT) implanted $\mathrm{SiO}_{2}$ as-implanted and after annealing at $950^{\circ} \mathrm{C}$ and $1100^{\circ} \mathrm{C}$ for $\mathrm{lh}$ in $\mathrm{Ar}+4 \% \mathrm{H}_{2}$.

3. PL spectra from Si nanocrystals formed in fused $\mathrm{Si}$ after annealing in either $\mathrm{Ar}+4 \% \mathrm{H}_{2}, \mathrm{Ar}+4 \% \mathrm{D}_{2}$ (dashed line), or pure Ar.

4. Hydrogen depth profiles from a thermal oxide as-implanted with $\mathrm{Si}$ (dashed) and annealed at $1100^{\circ} \mathrm{C}$ for $\mathrm{lh}$ in $\mathrm{Ar}+4 \% \mathrm{H}_{2}$ (solid) or in $\mathrm{Ar}$ (dotted).

5. Maximum PL yield (open circles) and retained $H$ (open squares) vs. anneal temperature from $S i$ nanocrystals formed in a thermal oxide by annealing in $\mathrm{Ar}+4 \% \mathrm{H}_{2}$ and subsequently annealed a second time in only Ar. For comparison, the maximum PL yield for a single anneal in either $\mathrm{Ar}+4 \% \mathrm{H}_{2}$ (filled circle) or Ar (filled triangle) are plotted. The hydrogen yield is normalized to the $\mathrm{PL}$ yield for a single anneal in $\mathrm{Ar}+4 \% \mathrm{H}_{2}$.

6. Deutcrium profiles following annealing at $1100^{\circ} \mathrm{C}$ for $1 \mathrm{~h}$ in $\mathrm{Ar}+4 \% \mathrm{D}_{2}$ or $\mathrm{Ar}+4 \% \mathrm{H}_{2}$.

7. Comparison of TRIM calculation for $\mathrm{Si}$ implantation into $\mathrm{SiO}_{2}$ (solid line) and the measured bulk $\mathrm{H}$ distribution (dotted line) following annealing in $\mathrm{Ar}+4 \% \mathrm{H}_{2}$ at $1100^{\circ} \mathrm{C}$ for $1 \mathrm{~h}$. 

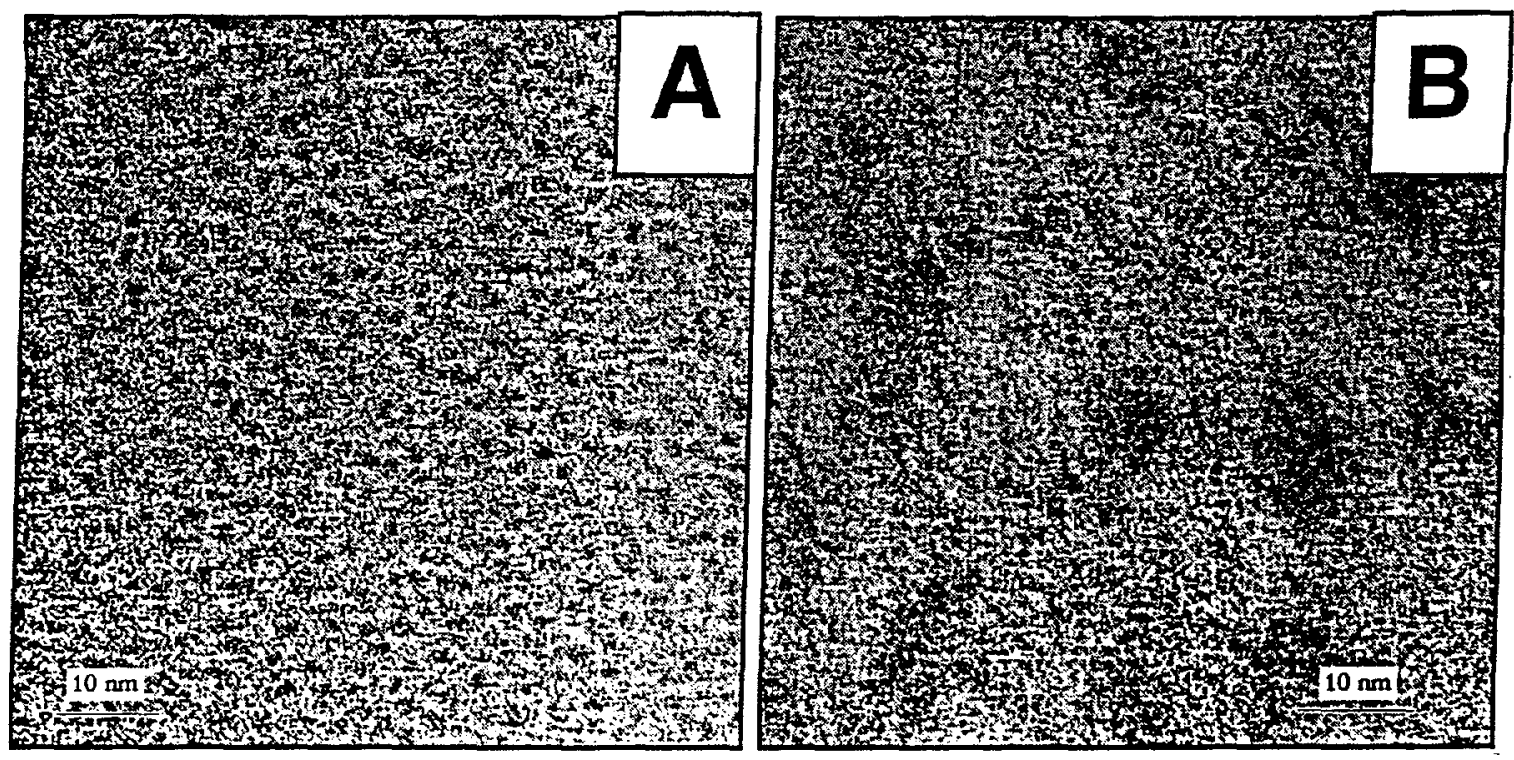

Fig. 1 Cross-section micrographs showing $\mathrm{Si}$ nanocrystals formed in $\mathrm{SiO} 2$ following annealing of uniform excess Si implantation of (a) $5 \times 10^{21} / \mathrm{cm}^{3}$ and (b) $2 \times 10^{22} / \mathrm{cm}^{3}$ at $1100^{\circ} \mathrm{C}$ for th in flowing $\mathrm{Ar}+4 \% \mathrm{H}_{2}$. 


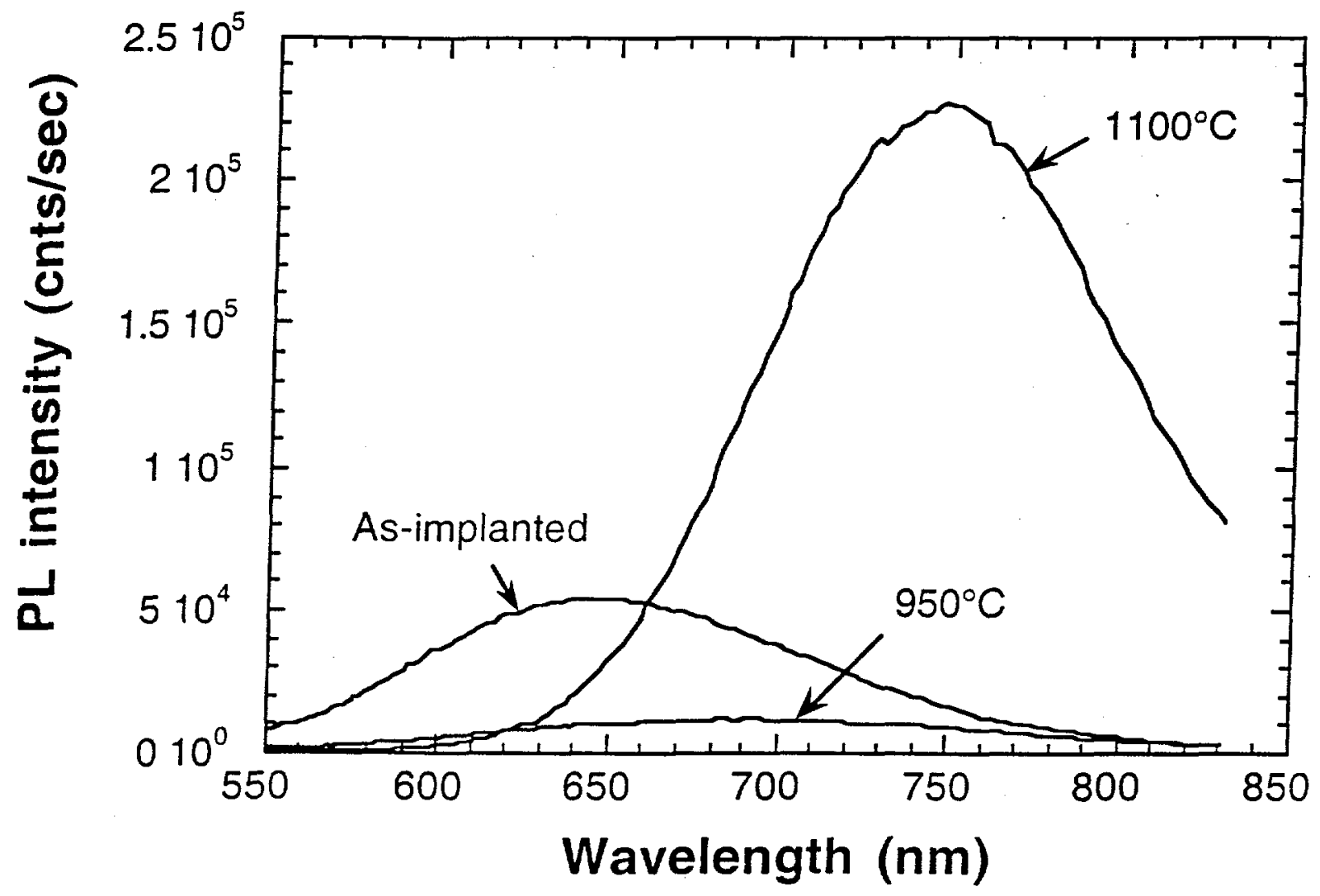

Fig. 2 PL spectra from Si $\left(400 \mathrm{keV}, 1.5 \times 10^{17} / \mathrm{cm}^{2}\right.$, RT) implanted $\mathrm{SiO}_{2}$ as-implanted and after annealing at $950^{\circ} \mathrm{C}$ and $1100^{\circ} \mathrm{C}$ for $\mathrm{lh}$ in $\mathrm{Ar}+4 \% \mathrm{H}_{2}$. 


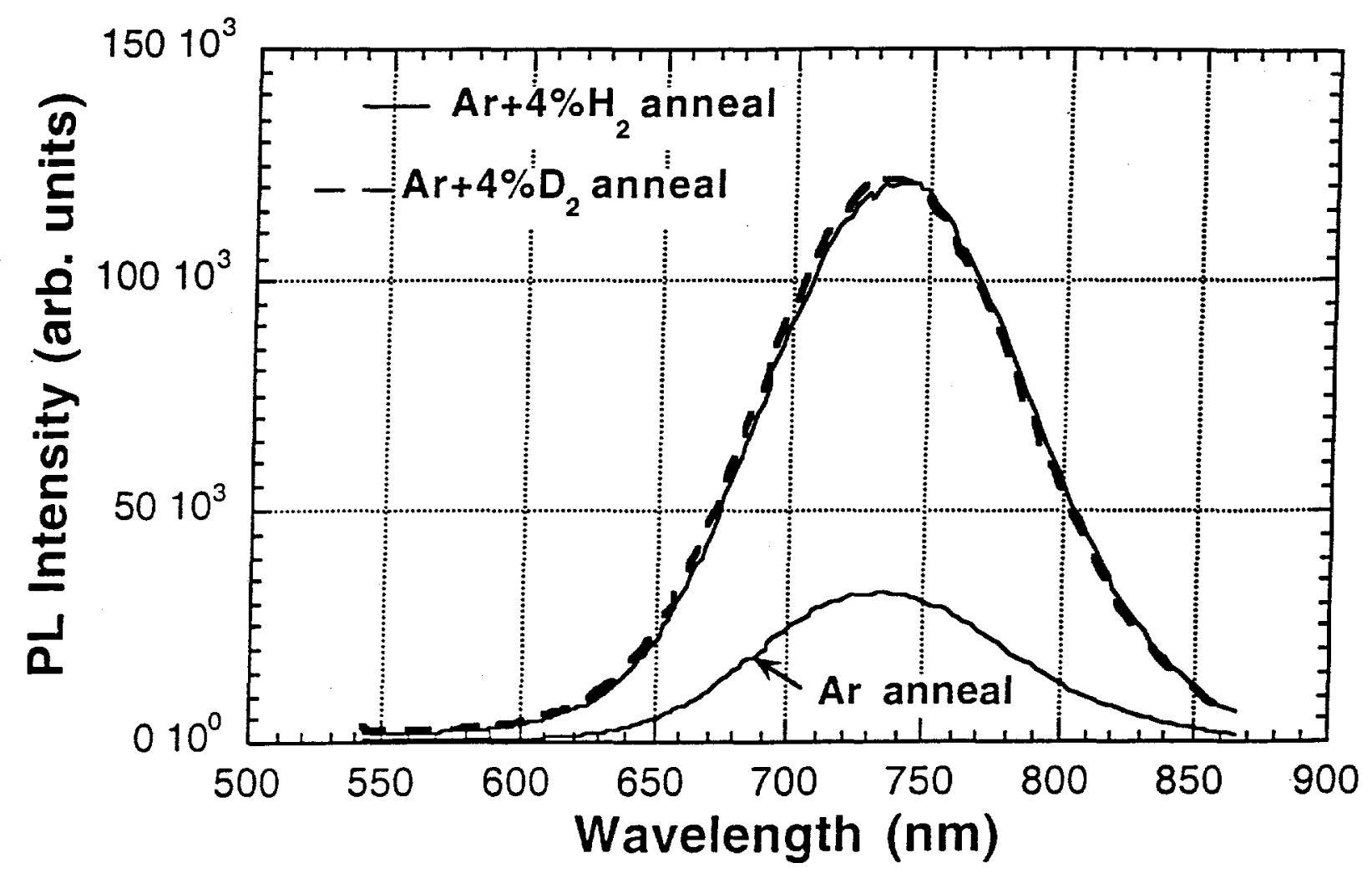

Fig. 3. PL spectra from $\mathrm{Si}$ nanocrystals formed in fused $\mathrm{Si}$ after annealing in either $\mathrm{Ar}+4 \% \mathrm{H}_{2}$, $\mathrm{Ar}+4 \% \mathrm{D}_{2}$ (dashed line), or pure Ar. 


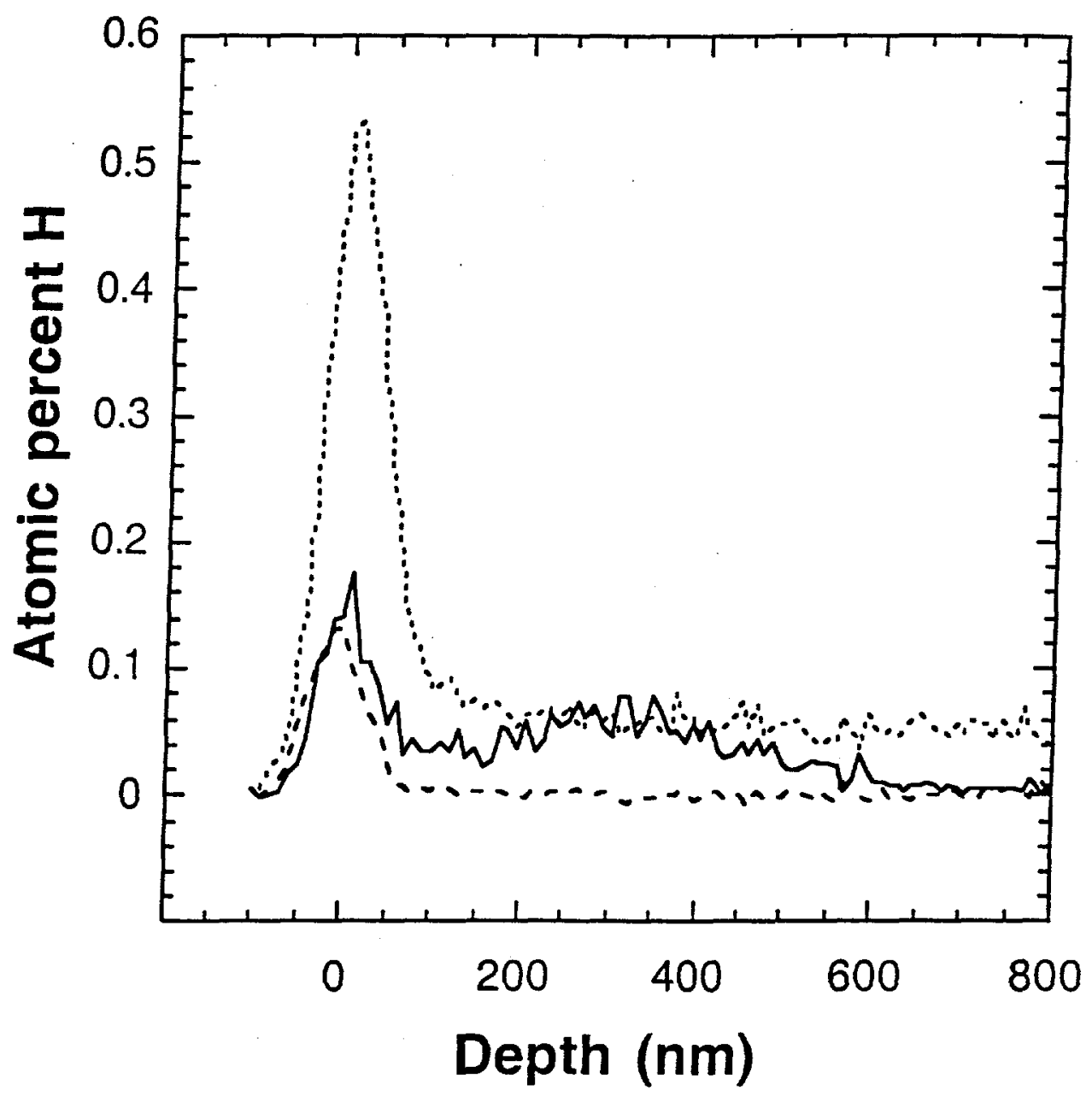

Fig. 4. Hydrogen depth profiles from a thermal oxide as-implanted with Si (dashed) and annealed at $1100^{\circ} \mathrm{C}$ for $\mathrm{lh}$ in $\mathrm{Ar}+4 \% \mathrm{H}_{2}$ (solid) or in $\mathrm{Ar}$ (dotted). 


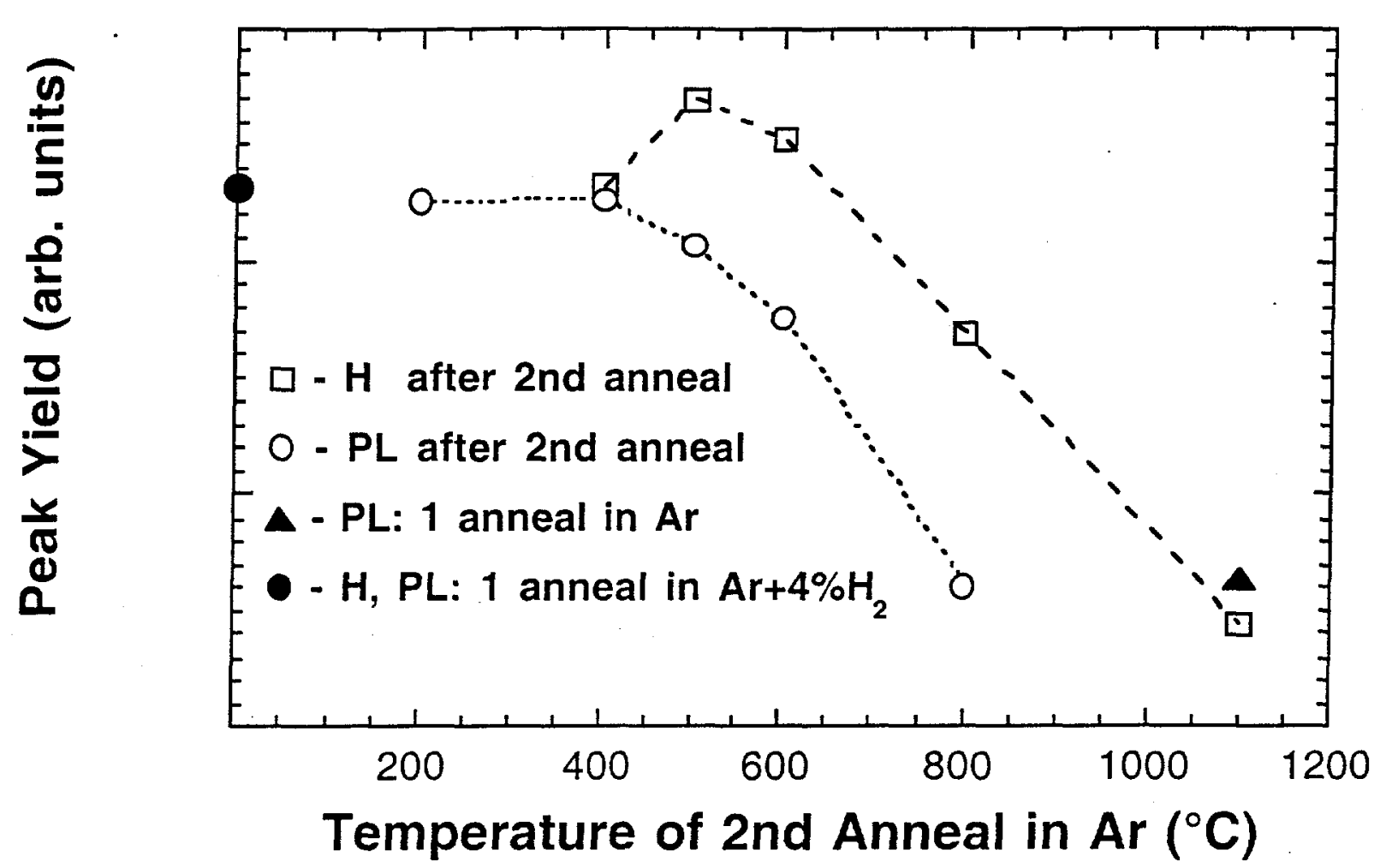

5. Maximum PL yield (open circles) and retained H (open squares) vs. anneal temperature from $\mathrm{Si}$ nanocrystals formed in a thermal oxide by annealing in $\mathrm{Ar}+4 \% \mathrm{H}_{2}$ and subsequently annealed a second time in only Ar. For comparison, the maximum PL yield for a single anneal in either $\mathrm{Ar}+4 \% \mathrm{H}_{2}$ (filled circle) or Ar (filled triangle) are plotted. The hydrogen yield is normalized to the $\mathrm{PL}$ yield for a single anneal in $\mathrm{Ar}+4 \% \mathrm{H}_{2}$. 


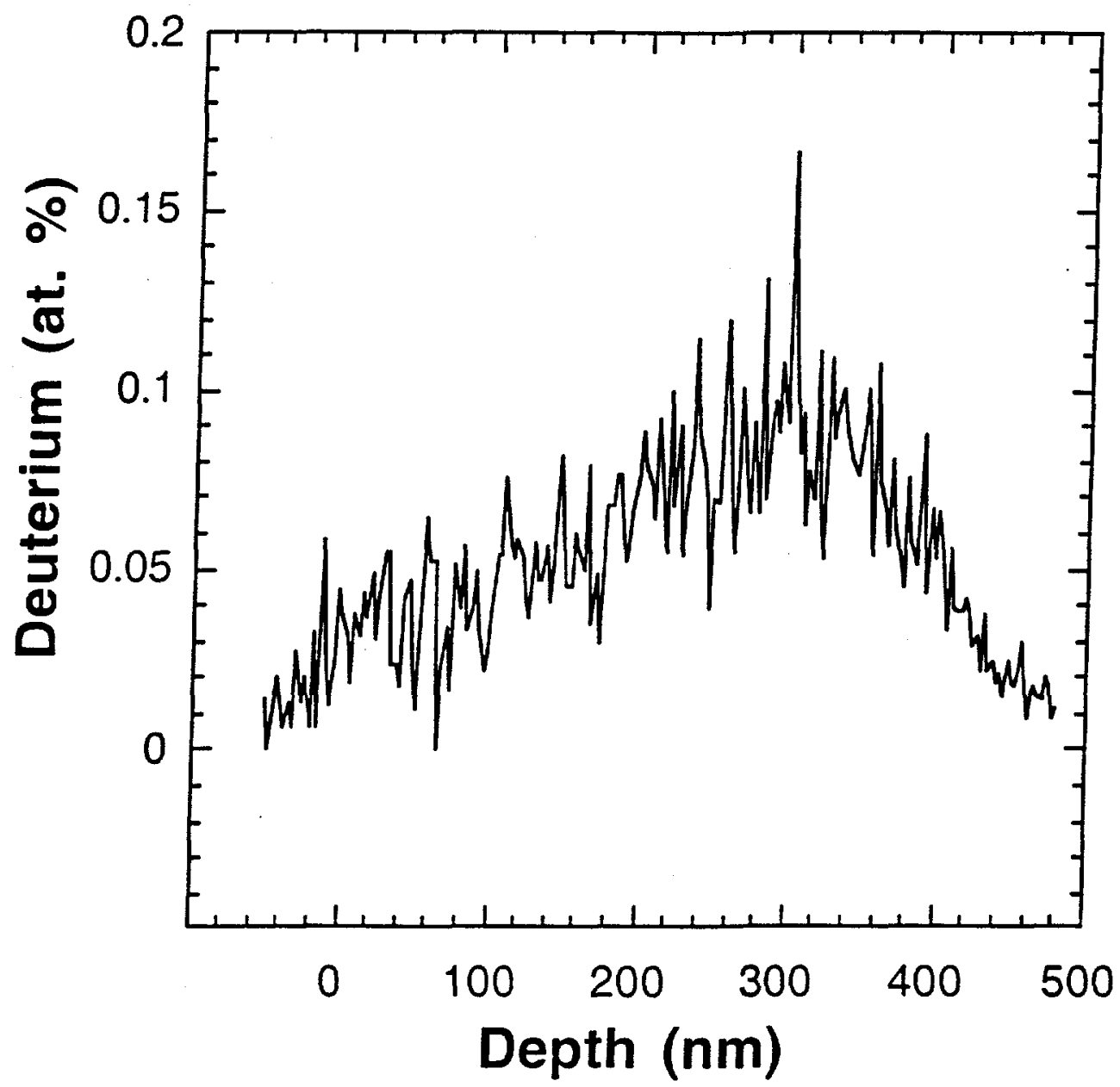

Fig. 6 Deuterium profiles following annealing at $1100^{\circ} \mathrm{C}$ for $1 \mathrm{~h}$ in $\mathrm{Ar}+4 \% \mathrm{D}_{2}$ or $\mathrm{Ar}+4 \% \mathrm{H}_{2}$. 


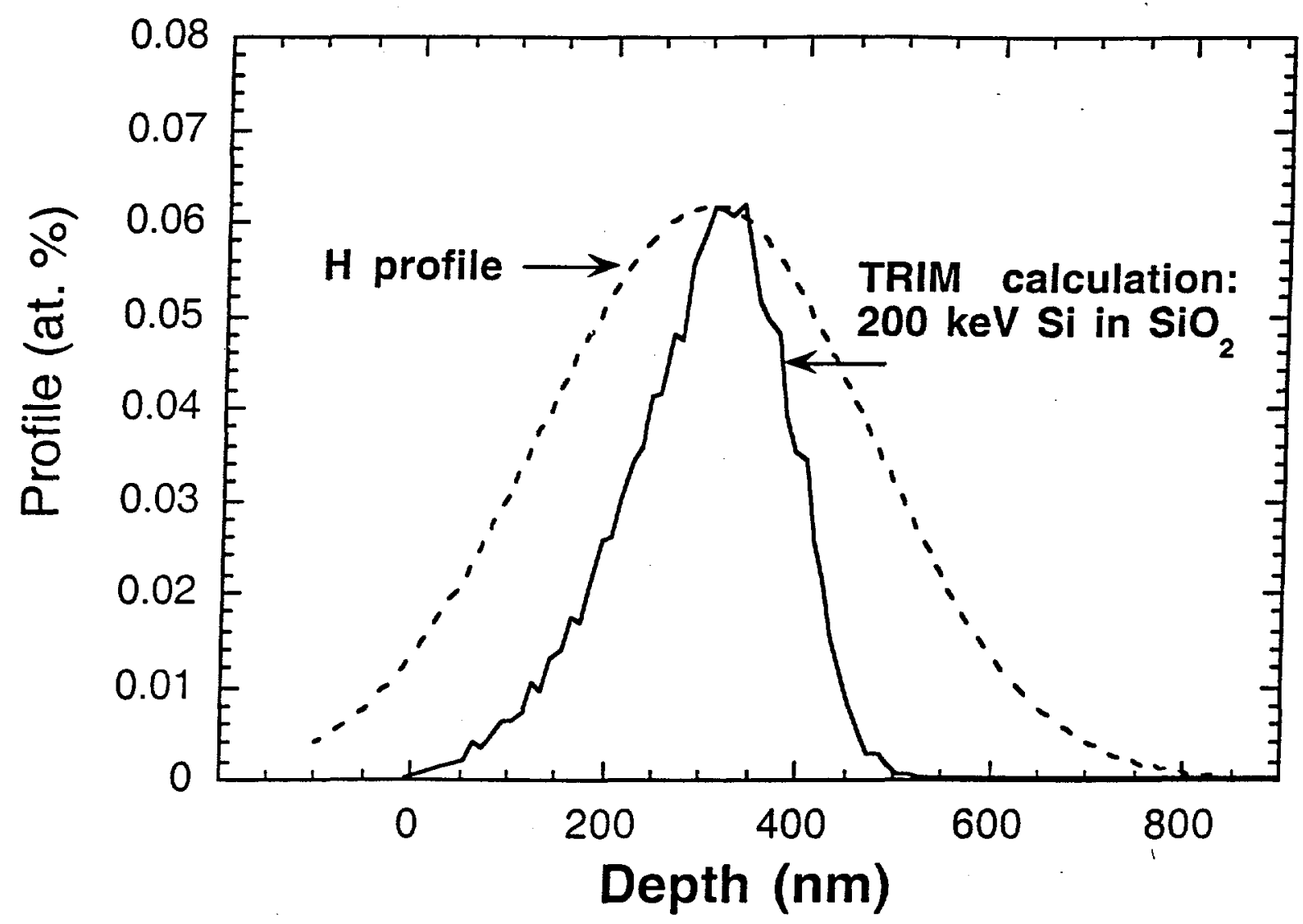

Fig. 7. Comparison of TRIM calculation for $\mathrm{Si}$ implantation into $\mathrm{SiO}_{2}$ (solid line) and the measured bulk $\mathrm{H}$ distribution (dotted line) following annealing in $\mathrm{Ar}+4 \% \mathrm{H}_{2}$ at $1100^{\circ} \mathrm{C}$ for $\mathrm{I} \mathrm{h}$. 